\title{
Afinal, o que é Seleção por Consequências?
}

\author{
Monalisa de Fátima Freitas Carneiro Leão \\ Universidade Federal do Pará \\ Marcus Bentes de Carvalho Neto \\ Universidade Federal do Pará
}

\begin{abstract}
RESUMO
A proposta de Skinner intitulada 'Seleção por Consequências' parece garantir uma filiação a uma epistemologia selecionista. Tal noção, entretanto, carece de uma definição consensual na área. O objetivo deste artigo é propor uma conceituação da proposta skinneriana. Para tanto, realizou-se uma análise dos principais textos do autor sobre o tema, a fim de delimitar os aspectos que julgamos serem suficientes e definidores dessa proposta científica. Concluímos que a 'seleção por consequências' pode ser definida como um modo causal fundamentado em uma relação de interdependência probabilística entre eventos, a qual explica a origem e a evolução do fenômeno comportamental como produto de três histórias de variação e seleção: filogenética, ontogenética e cultural.

Palavras-chave: selecionismo; explicação do comportamento; análise do comportamento; Skinner; variação; seleção.
\end{abstract}

\begin{abstract}
After all, what's Selection by Consequences?

The Skinner's proposal entitled 'Selection by Consequences' seems to ensure a commitment to selectionist epistemology. This notion, however, lacks a consensual definition in the area. The aim of this article is to propose a conceptualization of Skinnerian proposal. We have examined such explanatory proposal through an analysis of the main Skinnerian texts on the subject, in order to delimit the sufficient and defining aspects of this scientific proposal. We have concluded that 'selection by consequences' can be defined as a causal mode based on a probabilistic interdependence relationship between events, which explains the origin and evolution of behavioral phenomena as product of three histories of variation and selection: phylogenetic, ontogenetic and cultural.
\end{abstract}

Keywords: selectionism; explanation of behavior; behavior analysis; Skinner; variation; selection.

A proposta skinneriana de 'Seleção por Consequências', apresentada sistematicamente em 1981, tem sido explorada por diversos estudos no âmbito da Análise do Comportamento (e.g., Andery, Micheletto, \& Sério, 2000; Cruz \& Cillo, 2008; Donahoe, 2003, 2012; Donahoe, Burgos \& Palmer, 1992; Glenn \& Madden, 1995; Holth, 2016; Hull, Langman \& Glenn, 2001; Matos, 2003; Moxley, 1996, 2001; Palmer \& Donahoe, 1992; Reese, 2005), assim como a visão selecionista tem sido frequentemente apresentada como uma característica central da área (Catania, 2001). Apesar dessa centralidade, tal proposta explicativa é alvo de grandes debates, controvérsias, e carece de uma definição consensual. Consequentemente, o termo 'selecionismo', assim como o adjetivo 'selecionista', tão frequentemente aplicado à ciência analítico-comportamental, podem se referir a características muito distintas.

Alguns analistas do comportamento usam o termo 'seleção por consequências', assim como a variação 'selecionismo', no sentido de uma nova noção de causalidade, alternativa àquela empregada pela Mecânica Clássica (Micheletto, 1995; Moxley, 1996, 2001; Cruz \& Cillo, 2008). Micheletto (1995), por exemplo, ao analisar a construção da ciência skinneriana com ênfase na sua proposta metodológica, afirmou que no texto de 1981, Skinner "apresenta, orientado pelos princípios da seleção natural, um novo tipo de causalidade e um redimensionamento das determinações a que o comportamento está submetido" (p. 145). Cruz e Cillo (2008) também compartilharam desse uso do termo, ao afirmarem que se trata de um "modelo 
causal único... modelo este que marca de forma decisiva a desvinculação do behaviorismo radical ao mecanicismo e destaca, ao mesmo tempo, uma posição eminentemente selecionista" (p. 382).

Outra acepção de uma proposta selecionista refere-se a um tipo de explicação para lidar com a complexidade. Tal uso tem sido frequentemente compartilhado por Donahoe e colaboradores (Donahoe, 2003, 2012; Donahoe, Burgos, \& Palmer, 1992; Palmer \& Donahoe, 1992). Em seu artigo intitulado 'Selectionism', por exemplo, Donahoe (2003) adotou como um de seus objetivos "caracterizar selecionismo como uma abordagem geral para a compreensão dos fenômenos complexos como produtos de processos relativamente simples agindo ao longo do tempo" (p. 103). Para o autor, o processo de seleção implicaria em três passos intrinsecamente inter-relacionados: variação, seleção e retenção. A complexidade seria, então, um possível produto cumulativo da relação entre essas três fases. Nesse sentido, segundo o autor, o termo 'selecionismo' não se refere exclusivamente ao modo explicativo skinneriano, mas a um tipo de explicação para a complexidade também almejada pela biologia evolutiva.

Apesar de uma ênfase no processo de seleção ao longo da história da ciência e, em particular, da história da Análise do Comportamento (Hunziker \& Moreno, 2000; Staddon \& Simmelhag, 1971), o termo 'selecionismo' vinculado à proposta skinneriana frequentemente implica no reconhecimento do papel fundamental das variações para a ocorrência de seleção e, consequentemente, da própria evolução. Tal reconhecimento levou alguns autores a usarem esse critério para diferenciar uma perspectiva selecionista de outras propostas explicativas. Palmer e Donahoe (1992), por exemplo, também fizeram uso desse critério, ao argumentarem que a principal diferença entre o essencialismo e o selecionismo está relacionada ao tratamento oferecido à variação: "A principal diferença entre essencialismo e selecionismo, então, é que selecionismo trata a variabilidade dentro das classes do fenômeno como fundamental, enquanto o essencialismo a considera como uma ilusão irrelevante" (p. 1346).

Outras inconsistências conceituais podem ainda ser levantadas, como por exemplo, a suposta vinculação do termo 'selecionismo' ao processo de se- leção e/ou condicionamento operante. Como destacou Cleaveland (2002), "uma psicologia selecionista tem frequentemente sido mantida como sinônimo de condicionamento operante" (p. 75). Seriam então 'seleção por consequências' e 'condicionamento operante' termos equivalentes? Reese (2005), entretanto, ao propor uma análise conceitual de selecionismo, argumentou que 'seleção por consequências', análoga à seleção natural, é o resultado em vez de processo. Segundo o autor, na ontogenia, os processos comportamentais seriam os próprios procedimentos que denominamos condicionamento operante. Nesse sentido, 'seleção por consequências' implicaria reforçamento e/ou condicionamento operante, mas não seriam termos equivalentes. Ainda sobre o tema, parece haver uma dificuldade conceitual com relação à própria definição dos termos chaves dessa acepção, como variação e seleção. Como apontado por Hull et al. (2001), variação foi as vezes tratada como parte do processo de seleção, as vezes como uma precondição para tal processo.

Essa falta de delimitação clara e inequívoca para caracterizar o termo traz algumas implicações para a Análise do Comportamento, visto que a 'seleção por consequências', ou por vezes, o 'selecionismo', são adotados como elementos críticos para diferenciar a proposta explicativa analítico-comportamental de outras explicações tradicionais do fenômeno psicológico, classificadas como, por exemplo, essencialismo (Palmer \& Donahoe, 1992), fisicalismo (Leão \& Laurenti, 2009), mentalismo (Zilio \& Carrara, 2008), e mecanicismo (Cruz \& Cillo, 2008). Além disso, a ambiguidade de características atribuídas ao modo explicativo skinneriano pode dificultar discussões que avaliem a efetividade, plausividade e adequação da analogia científica entre 'seleção por consequências' na ontogenia e a noção darwiniana de seleção natural na biologia evolutiva.

A problemática de uma definição consensual do termo também traz implicações para a própria avaliação do impacto desse princípio explicativo sobre a produção científica atual da área. Tonneau e Sokolowski (2000), por exemplo, afirmaram que apesar do grande impacto da analogia selecionista e da proposta de 'seleção por consequências' na Análise do Comportamento, via discussões teóricas e livros-textos, de fato, um olhar mais cuidadoso sobre as pesquisas desenvolvidas na área 
revela que não há nenhum programa de pesquisa que sustente tal analogia, muito menos indícios de pesquisas fundamentadas no selecionismo. De acordo com os autores:

A linguagem metafórica reminiscente da biologia evolutiva é então imposta sobre os dados de modo que têm sido atualmente produzidos e interpretados sem qualquer inspiração da metáfora de seleção. Se nenhuma pista de selecionismo pode ser encontrada no trabalho inicial de Skinner, desenvolvimentos mais recentes na pesquisa operante (e.g., Davison \& McCarthy, 1988) também não carregam nenhuma pista de selecionismo. (Tonneau \& Sokolowski, 2000, pp. 158-159)

$\mathrm{Na}$ tentativa de explorar paralelos de uma proposta explicativa comportamental com a teoria evolutiva orgânica, Glenn e Madden (1995) reconheceram a necessidade de discussões voltadas para a caracterização de uma perspectiva selecionista: "Embora selecionista seja um adjetivo frequentemente aplicado ao paradigma analítico comportamental, o trabalho sério de explicar o que isso significa mal começou" (p. 249). Assim como as autoras, acredita-se que trabalhar em prol de uma melhor caracterização do modo explicativo selecionista pode trazer consequências que inclui tanto avanços metodológicos como filosóficos para a Análise do Comportamento, além de propiciar um diálogo mais efetivo e consistente com a Biologia Evolutiva.

Considerando que o termo 'seleção por consequências' está intrinsecamente relacionado à proposta skinneriana, apresentada em 1981, no artigo intitulado Selection by Consequences, este trabalho examina, a partir da literatura primária (Selection by Consequences: Skinner, 1981; Some Consequences of Selection: Skinner, 1984; Can Psychology be a Science of Mind?: Skinner, 1990) as principais características referenciadas pelo autor a esse termo. Pretende-se, por meio desta análise, apresentar uma conceituação, a partir da delimitação dos aspectos que julgamos serem suficientes e definidores dessa proposta científica.

Antes disso, é válido esclarecer alguns pontos. Não se pretende oferecer com este texto uma unidade narrativa que esgotará as discussões a respeito da definição do termo em questão, e que orientará a produção de conhecimento daqui em diante. Ademais, a proposta desta pesquisa conceitual não está vinculada à ideia tradicional de interpretação como instrumento para revelar o verdadeiro, definitivo e essencial sentido de um con- ceito. Sendo assim, a escolha de se ater a textos skinnerianos esteve sob controle do fato de que, por ser B. F. Skinner o proponente da proposta explicativa vinculada ao conceito, acredita-se que um exame de como o próprio Skinner (1981, 1984, 1990) caracterizou sua proposta explicativa pode servir como pano de fundo para pesquisas futuras, como uma investigação histórica desse conceito ao longo de seus escritos, assim como uma análise das variações do termo na literatura secundária sobre o tema. Por fim, ainda se limitando à obra skinneriana, essa interpretação não esgota outras interpretações do mesmo conceito na obra desse autor, pois os autores compartilham da ideia de que a construção desta interpretação envolveu uma inter-relação única entre autor, leitor e texto (Laurenti \& Lopes, 2016).

\section{A PROPOSTA SKINNERIANA DE SELEÇÃO POR CONSEQUÊNCIAS}

Diante da pluralidade de sentidos que o termo 'seleção por consequências' pode assumir, resta-nos, questionar: quais aspectos seriam suficientes para caracterizar uma perspectiva selecionista, fundamentada na proposta de 'seleção por consequências', de um ponto de vista skinneriano? Na tentativa de responder a essa questão, avaliou-se, a partir de seus três textos emblemáticos sobre o tema, como o próprio Skinner (1981, 1984, 1990) caracterizou sua proposta explicativa. A partir dessa análise, três aspectos foram julgados necessários e suficientes para definir tal proposta, os quais serão descritos a seguir.

\section{O Papel Seletivo das Consequências: Um Novo Mo- do Causal}

Já no resumo do artigo de 1981, a primeira definição apresentada por Skinner (1981) é que 'seleção por consequências' é um modo causal. É com base nessa acepção que Skinner reconheceu que tal modo causal não se limita à sua proposta de explicação do comportamento, mas refere-se a um tipo de relação de dependência entre eventos, a qual foi primeiramente reconhecida na teoria darwiniana de seleção natural. Com isso, o autor explicou que 'seleção por consequências' surgiu como um modo causal quando, na história da espécie, uma molécula adquiriu a capacidade de reprodução. Reprodução, então, foi a primeira consequência que possibilitou, nesse caso, a origem e evolução das espécies.

Skinner (1981, 1984, 1990) enfatizou que tal modo 
causal também explica a origem e manutenção do comportamento ao longo da vida de um indivíduo, assim como a evolução de práticas no nível cultural. Mas, esse tipo de explicação para o fenômeno comportamental só foi possível porque uma suscetibilidade a certos tipos de consequências, juntamente com um suprimento de comportamento indiferenciado, foram selecionados como traços via seleção natural. Com isso, certos eventos consequentes ao comportamento adquiriram função seletiva, dando origem à configuração de um segundo tipo de 'seleção por consequências', denominado condicionamento operante. A evolução desse processo, paralelo ao condicionamento respondente, possibilitou aos organismos adquirirem comportamentos apropriados às condições ambientais relativamente instáveis, e, consequentemente, a reprodução diante de tais condições. Skinner (1984) conferiu ao condicionamento operante "a mais clara evidência que temos do processo de seleção por consequências" (p. 503), uma vez que ele evidencia esse tipo de relação de dependência entre eventos em processo.

A definição de 'seleção por consequências' como um modo causal the confere o papel de um princípio explicativo responsável pela origem e pela novidade (Skinner, 1981, 1984, 1990). Dando as palavras a Skinner (1984): "Seleção é um modo causal somente no sentido de causar novidade - quer seja na origem das espécies, na modelagem de novos operantes, ou na invenção de práticas culturais" (p. 506). É justamente a partir dessa proposta de explicar a originalidade que tal princípio foi caracterizado como alternativo a outras propostas explicativas. Skinner (1981) afirmou, por exemplo, que a diversidade foi por muito tempo explicada ou atribuída a um agente criador, como uma mente criativa, mas a seleção natural propôs uma explicação alternativa. Já em 1984, Skinner retomou esse ponto, agora para evidenciar a especificidade desse modo causal com relação àquele proposto pela Mecânica Clássica: "Como um modo explicativo, seleção é responsável somente pela novidade, pelas origens. Essa é a maneira na qual ela difere do modo causal da física” (p. 503).

O caráter alternativo do modo causal de 'seleção por consequências' nos permite destacar alguns pontos importantes desse princípio explicativo. Primeiramente, é notável nos escritos skinnerianos sua preocupação em destacar que 'seleção por consequências' é uma proposta de explicação que difere de explicações fundamentadas nos moldes causais da mecânica clássica. Skinner (1981) evidenciou que tal modo alternativo foi notado tardiamente na história da ciência, e sua rejeição prova- velmente foi devido à influência do mecanicismo como fundamento filosófico e metodológico que predominou nas ciências do século XIX, inclusive na Psicologia. Uma das características definidoras do modo causal selecionista é sua renúncia a um agente iniciador antecedente, o qual ocupa o papel de causa do comportamento. Nas palavras de Skinner (1981): "Resiste-se particularmente ao papel de seleção por consequências porque não há lugar para um agente iniciador como sugerido pela mecânica clássica" (p. 504). Em 1990, o autor complementou: "Em uma análise científica, histórias de variação e seleção ocupam o papel do agente iniciador. Não há lugar na análise científica do comportamento para uma mente ou self" (Skinner, 1990, p. 1209).

Paralelo à rejeição de um agente iniciador, o modo causal de 'seleção por consequências' também contraria a típica noção de causa como força ou agência que caracteriza a ideia mecanicista de causalidade (Chiesa, 1994/2006). Ao discutir controle de estímulos no âmbito das relações comportamentais, Skinner (1990) explicou que, em uma perspectiva selecionista, o estímulo antecedente exerce uma função alternativa: "A análise experimental do comportamento atribui um papel muito diferente ao estímulo. [...] Uma resposta operante é mais provável de ocorrer na presença de um estímulo que esteve presente quando ela foi reforçada" (Skinner, 1990, p. 1207). Da mesma forma, o efeito seletivo do evento consequente é descrito em termos probabilísticos: "no condicionamento operante, comportamento é reforçado, no sentido de fortalecido ou mais provável de ocorrer, por certos tipos de consequências. . .." (p. 1206). Portanto, 'seleção por consequências' substitui a noção de causalidade mecanicista por uma relação de interdependência probabilística entre eventos antecedentes, resposta e consequência.

Outra característica que justifica o caráter alternativo desse princípio explicativo diz respeito à proposta de uma explicação científica predominantemente histórica. Isso porque "somente consequências passadas figuram na seleção" (Skinner, 1981, p. 503). Na seleção natural, são as consequências passadas de sobrevivência da espécie; no condicionamento operante, são as consequências de reforçamento que ocorreram na história do indivíduo; e na evolução cultural, são as consequências passadas de sobrevivência da cultura. Por isso, Skinner (1990) enfatizou que "em uma análise científica, histórias [ênfase adicionada] de variação e seleção ocupam o papel do agente iniciador" (p. 1209). Esse aspecto é incompatível com um princípio explica- 
tivo fundamentado nos cânones mecanicistas, o qual implica uma relação de contiguidade entre eventos, justificando a necessidade de se inferir elos mediacionais para cumprir a exigência de uma relação causal espacial e temporal imediata (Chiesa, 1994/2006). 'Seleção por consequências', portanto, ao se caracterizar como uma explicação histórica, não atribui somente ao ambiente imediato um papel explicativo, mas também à história ambiental da espécie, indivíduo e cultura.

O papel da história nesse princípio explicativo evidencia que não há espaço para propósito ou intenção no processo evolutivo (Skinner, 1981). Uma espécie particular possui um determinado traço biológico, não para que seus membros possam se favorecer diante de certas circunstâncias ambientais, mas porque alguns membros, os quais sofreram variação relacionada a esse traço, favoreceram-se diante de tais circunstancias, e, então, tornaram-se mais prováveis de transmitir tal variação. Similarmente, um indivíduo não se comporta em função de possíveis consequências futuras, mas de consequências passadas similares que modelaram e mantiveram tal comportamento. No âmbito cultural, de forma análoga, práticas não são adotadas a fim de que a sobrevivência do grupo se torne mais provável, mas sim devido às consequências que favoreceram a sobrevivência desse ou de outro grupo quando práticas similares foram adotadas.

Assim como não há espaço para propósito ou intenção no modo causal selecionista, também não deve haver expectativas de que evolução implique em perfeição. De fato, como também sugeriu Darwin (1859), Skinner (1981) mencionou que podemos interferir no processo de seleção na tentativa de resolver muitos dos subprodutos indesejáveis da evolução, como superpopulação e desgaste ambiental. Isso ocorre, por exemplo, quando geneticistas modificam características biológicas de uma espécie, ou quando professores modificam comportamentos em sala de aula, ou quando gestores planejam novas práticas culturais. Entretanto, tais variações precisam ser selecionadas. Isto é, "nenhuma dessas formas nos faz escapar da seleção por consequências ... nós devemos esperar que a seleção ocorra" (Skinner, 1981, p. 504). Além disso, o nosso próprio comportamento de intervir nesse processo não pode ser tratado como um agente iniciador porque ele próprio é produto de histórias de variação e seleção. Skinner (1981), então, concluiu:

É comumente dito que a espécie humana é agora capaz de controlar sua própria genética, seu próprio comportamento e seu próprio destino, mas ela não o faz no sentido em que o termo controle é empregado na Mecânica Clássica. Não o faz pelo simples fato de que coisas vivas não são máquinas: a seleção por consequências faz a diferença. (p. 504)

\section{A Complementaridade Entre Variação e Seleção}

A despeito da proposta de 'seleção por consequências' fazer referência explícita somente ao processo de seleção, tal princípio pressupõe a relação complementar intrínseca de variações (Skinner, 1981, 1984, 1990). Em diversas passagens do texto de 1990, Skinner pareceu se preocupar em deixar essa relação mais evidente, fazendo sempre menção aos dois termos: "o comportamento do organismo como um todo é produto de três tipos de variação e seleção [ênfase adicionada]" (p. 1206); "todos os tipos de variação e seleção [ênfase adicionada] tem certas falhas. ..." (p. 1206). Ao fazer inferência à etologia, análise do comportamento e antropologia, por exemplo, Skinner as classificou como "um grupo de três ciências interessadas em variação e seleção [ênfase adicionada]" (p. 1208). A primeira estaria relacionada à variação e seleção no nível filogenético; a segunda no nível individual; e a terceira se voltaria para esses dois processos ocorrendo a nível cultural.

Ao descrever o condicionamento operante, Skinner (1990) explicou que se trata de um processo por meio do qual "variações [ênfase adicionada] no comportamento do indivíduo são selecionadas [ênfase adicionada] por características do ambiente. ..." (p. 1206). Logo mais adiante, o autor mencionou que uma das falhas desse segundo tipo de variação e seleção está justamente relacionada ao fato de que "seleção deve esperar por variação" (p. 1206). Isso não é uma especificidade do condicionamento operante, pois, tanto na seleção natural como na evolução cultural, seleção só ocorre se houver variações. A diferença é que a nível individual, a evolução não pode ser tão lenta, visto que precisa ocorrer durante o tempo de vida de um único indivíduo. A ocorrência da primeira resposta foi solucionada, em parte, segundo o autor, por meio da evolução de processos pelos quais os indivíduos se beneficiam de comportamentos já adquiridos por outros, como a imitação.

Como vimos na descrição do aspecto anterior, Skinner (1981) admitiu que, de certa forma, podemos intervir no processo evolutivo. Podemos alterar a composição genética do organismo ou contingências de sobrevivência; ou introduzir novos padrões de comportamento ou manipular contingências de reforçamento; 
assim como criar novas práticas culturais ou arranjar contingências especiais de sobrevivência da cultura. Isto é, "podemos somente trabalhar por meio de variação e seleção" (p. 504), quando o objetivo é intervir no curso da evolução. Esse tipo de planejamento, tanto de variações como de seleção, no entanto, nem sempre é possível. Por isso, muito se questiona a validade do princípio de 'seleção por consequências', visto que muitas espécies se mantem constantes por milhares e milhares de anos, assim como certas práticas culturais e padrões de comportamentos individuais. Skinner (1981) respondeu a esse tipo de questionamento remetendo às limitações quando não há complementaridade entre os processos de variação e seleção. Isto é, "ou nenhuma variação ocorreu, ou aquelas que ocorreram não foram selecionadas pelas contingências em vigor" (p. 502). Logo, evolução, segundo a proposta de 'seleção por consequências', depende intrinsecamente da complementaridade entre variação e seleção.

Skinner (1990) mencionou outra falha do processo de variação e seleção, a partir da qual se torna possível discutir a natureza das variações a partir de uma perspectiva selecionista. Nas palavras do autor: "Variações são randômicas e contingências de seleção acidentais" (p. 1207). O caráter randômico das variações está relacionado ao fato de que, nos três tipos de história evolutiva, sua ocorrência independe das demandas ambientais. Na seleção natural, isso significa dizer que a probabilidade de ocorrência de uma dada mutação, principal processo responsável pelas variações genéticas, não tem relação com a utilidade que tais variações possam vir a ter (Futuyma, 1998). Da mesma forma, as variações comportamentais que ocorrem ao longo do tempo de vida do indivíduo são aleatórias, no sentido de que, no mínimo, não estão relacionadas às contingências reforçadoras prevalecentes no momento de sua ocorrência. Na mesma linha de argumentação, a ocorrência de variações nas práticas culturais independe de sua efetividade para a sobrevivência do grupo no qual ocorrem (Skinner, 1990).

Ao reconhecer o processo de variação como complementar ao de seleção, Skinner (1990) parece conferir um estatuto positivo à natureza casual desse processo, argumentando que as casualidades, junto com a seleção, podem dar origem a produtos fascinantes no curso da evolução. Isso fica evidente nas descrições de biografias de escritores, artistas, cientistas e compositores, por exemplo, as quais revelam a importância dos acasos na produção de comportamentos originais. Vale destacar que originalidade, nesse sentido, não abre flanco para explicações que inferem agentes iniciadores metafísicos, como uma mente criativa, assim como não há espaço para explicações tradicionais de liberdade, mas deve ser entendida como produto de histórias de variação e seleção. Nas próprias palavras de Skinner: "Se há liberdade, ela é para ser encontrada no caráter randômico das variações. Se novas formas de comportamento são criadas, elas são criadas por seleção. As falhas na variação e seleção são uma origem de problemas fascinantes" (p. 1208). Mais adiante, o autor concluiu: “As coisas interessantes na vida vêm dos caprichos da variação e seleção" (p. 1208).

\section{Três Histórias de Variação e Seleção}

Uma vez que os três aspectos definidores da proposta explicativa denominada 'seleção por consequências' estão intrinsecamente relacionados, esse último aspecto ficou implícito em algumas passagens das descrições dos dois critérios anteriores. Tal aspecto referese ao fato de que 'seleção por consequências' é uma proposta de explicação do comportamento no âmbito de três histórias ou tipos de variação e seleção (Skinner, 1981, 1984, 1990). Retomando as palavras de Skinner (1981): "Seleção por consequências é um modo causal. . . .Foi primeiramente reconhecida na seleção natural, mas explica, também, a modelagem e manutenção do comportamento do indivíduo e a evolução das culturas" (p. 501). Em 1990, Skinner reafirmou que "o comportamento do organismo como um todo é produto de três tipos de variação e seleção" (p. 1206).

O primeiro tipo de variação e seleção foi reconhecido na seleção natural, o qual explica a mudança evolutiva dos seres vivos, incluindo, consequentemente, a origem e evolução de aspectos comportamentais típicos da espécie (Skinner, 1981, 1984, 1990). A teoria de seleção natural foi proposta por Charles Darwin, em 1859, no livro intitulado A origem das espécies. Como um tipo de "seleção por consequências", essa teoria pressupõe um modo causal selecionista, a partir do qual o principal processo de modificação ou evolução é a ação da seleção natural sobre a variação individual (Futuyma, 1998). Ao defender que cada um dos três níveis evolutivos teria sua própria disciplina, Skinner, em 1981, defendeu que a evolução das espécies ficaria a cargo da Biologia, e em 1990, classificou a seleção natural do comportamento das espécies como objeto de estudo da Etologia.

A seleção natural, entretanto, prepara a espécie somente para um ambiente similar àquele no qual ela foi selecionada. A evolução de dois processos, condiciona- 
mento operante e respondente, já mencionados anteriormente, possibilitou ao organismo adquirir comportamentos apropriados a novos ambientes e a lidar com condições ambientais instáveis (Skinner, 1981, 1984, 1990). Por meio do condicionamento respondente, respostas selecionadas, via seleção natural, devido ao seu valor de sobrevivência, ficaram sob controle de novos estímulos. Já no condicionamento operante, novas respostas se tornaram mais prováveis quando eram seguidas por determinadas consequências, as quais adquiriram esse poder de reforçamento na história evolutiva da espécie. Esse último processo, de acordo com a proposta skinneriana, foi caracterizado como o segundo tipo de 'seleção por consequências'. De forma análoga à seleção natural, Skinner explicou que o condicionamento operante pressupõe que o principal processo de modificação ou evolução é a ação do reforçamento sobre as variações comportamentais durante o tempo de vida do indivíduo. Além disso, Skinner (1981, 1990) ressaltou que esse tipo de 'seleção por consequências' é o objeto de estudo da Psicologia.

Como já mencionado, um padrão de comportamento imitativo, diferente daquele tipo de imitação que é produto da seleção natural, evoluiu quando contingências de reforçamento que induzem um organismo a se comportar de determinada maneira passaram a afetar um outro organismo quando esse se comportava de forma similar (Skinner, 1981, 1984, 1990). Paralelo à evolução de um repertório imitativo, um grande passo evolutivo ocorreu quando a musculatura vocal da espécie humana ficou sensível ao efeito seletivo das consequências reforçadoras. Isto é, quando a musculatura vocal ficou sob controle operante. Esse passo evolutivo possivelmente foi resultado da evolução via seleção natural de uma inervação especial da musculatura vocal, assim como de um suprimento indiferenciado de respostas vocais, o qual não estava fortemente sob controle de estímulos antecedentes e que serviria como matéria prima para o processo de seleção. A aquisição de novas respostas vocais tornou a espécie humana muito mais social, assim como possibilitou a evolução de um ambiente social como um locus para a ocorrência de variações e seleção, agora a nível grupal.

Tal evolução de ambientes sociais ou culturas foi caracterizada por Skinner $(1981,1984,1990)$ como um terceiro tipo de 'seleção por consequências', o qual pressupõe que o principal processo de modificação ou evolução da cultura é a ação das consequências de sobrevivência do grupo sobre a variação de práticas culturais. Apesar de apontá-la como um nível distinto, o autor esclareceu que a evolução de práticas culturais não implica em nenhum novo processo comportamental distinto daquele que caracteriza o segundo nível evolutivo. Skinner (1984) esclareceu esse ponto:

Donahoe pergunta se evolução cultural, ou a evolução de práticas culturais, é um tipo diferente de seleção. Eu acho que é, embora eu não veja nenhum processo comportamental novo. Eu acho que condicionamento operante explica a descoberta de novas práticas e sua transmissão a outros (especialmente mais jovens) membros de um grupo. (p. 504)

Skinner (1984), não obstante, salientou que se trata de um nível distinto, pois, mesmo que a manutenção e transmissão de práticas demandem o processo de condicionamento operante, a evolução de uma cultura implica em uma "contingência diferente de seleção" (p. 506). Isto porque, diferente do segundo nível evolutivo, "as práticas em si mesmo evoluem por causa das contribuições para o grupo" (p. 504). Esse terceiro nível seletivo, de acordo com o autor, seria de interesse da antropologia.

Skinner (1981) esclareceu que os três níveis evolutivos apresentam similaridades e diferenças entre eles. As similaridades estão relacionadas ao próprio fato de todos serem caracterizados como tipos distintos de 'seleção por consequências'. Isso implica que todos compartilham de um mesmo modo causal selecionista, e que explicam a evolução em seus respectivos níveis via relação entre os processos de variação e seleção: " $E m$ todos os três niveis [ênfase adicionada], uma mudança súbita, possivelmente ampla, é explicada como resultado da seleção de novas variações pelas contingências em vigor ou por novas contingências" (p. 502). Os três níveis, entretanto, correspondem a ciências distintas de variação e seleção e demandam tempos distintos para evolução. Além disso, a evolução de uma espécie, indivíduo ou cultura implica formas distintas de transmissão. Segundo Skinner, traços genéticos, assim como as práticas culturais, são transmitidos de geração a geração, mas "comportamento reforçado é 'transmitido' somente no sentido de permanecer parte do repertório do indivíduo" (p. 502). Frente a afirmações tradicionais de que uma característica de um nível pode explicar uma característica similar em outro nível, o autor ainda concluiu que "as contingências de seleção nos três níveis são muito diferentes, e a similaridade estrutural não atesta um princípio gerador comum" (p. 503).

\section{CONSIDERAÇÕES FINAIS}

Talvez 'selecionista' seja um dos principais adjeti- 
vos conferidos à ciência skinneriana, que se estende aos pesquisadores analítico-comportamentais. Essa caracterização decorre da proposta de Skinner (1981) de explicar o fenômeno comportamental a partir de um princípio denominado 'seleção por consequências'. Tal proposta, contudo, ainda se mostra um tema controverso, ao mesmo tempo em que não conta com uma definição consensual na área. Isto é, apesar de não serem necessariamente incompatíveis entre si, diferentes critérios são usados como definidores do termo, assim como para justificar a inclusão da ciência skinneriana em uma perspectiva selecionista. Essa pluralidade de sentidos que o termo alude pode confundir aspectos definidores da proposta skinneriana, com tendências selecionistas que não implicam na adoção de 'seleção por consequências' como um sistema explicativo geral do comportamento. Isso significa dizer que, como evidenciou Matos (2003), entre a opção por um posicionamento epistemológico que levaria ao selecionismo e o uso de 'seleção por consequências' como um modo explicativo do comportamento, há uma gama de variações.

$\mathrm{Na}$ tentativa de explorar os critérios usados por Skinner $(1981,1984,1990)$ para definir o termo, analisamos sua proposta de 'seleção por consequências' a partir de seus principais textos sobre o tema. Concluímos que três aspectos podem ser considerados definidores desse sistema explicativo selecionista: (1) um novo modo causal, o qual pressupõe um papel seletivo das consequências; (2) uma noção de evolução pautada na complementaridade entre os processos de variação e seleção; e, por fim, (3) uma proposta de explicação do comportamento ao longo de três histórias evolutivas. Em suma, 'seleção por consequências' pode ser definida como um modo causal fundamentado em uma relação de interdependência probabilística entre eventos, o qual explica a origem e evolução do fenômeno comportamental como sendo produto de três histórias de variação e seleção: filogenética, ontogenética e cultural.

Tal definição proposta pode auxiliar na dissolução de algumas controvérsias sobre o tema. A primeira delas se refere às datações imprecisas da adoção de um posicionamento selecionista de Skinner no decorrer de sua obra. Alguns autores, como Palmer e Donahoe (1992) defenderam que a ciência skinneriana pode ser considerada selecionista desde sua proposta científica inicial, já na década de 1930. Isso porque, segundo os autores, já nessa época Skinner adotou um tratamento selecionista para a variação. No entanto, será que o suposto reconhecimento da variabilidade como um aspecto fundamental do comportamento é suficiente para caracterizar o início da proposta skinneriana de explicação do comportamento como selecionista? Matos (2003), por outro lado, defendeu que a gênese de 'seleção por consequências' deveria ser investigada principalmente a partir de meados da década de 1960. Visto tais inconsistências, este estudo traz implicações diretas sobre tal problemática, pois se conclui que um posicionamento selecionista implica na adoção dos três critérios da noção de 'seleção por consequências', e não apenas um aspecto em detrimento de outro. Sendo assim, a delimitação desses critérios possibilita analisar quando exatamente Skinner adotou um posicionamento selecionista e diferenciar tal adoção de indícios do processo de construção dessa proposta explicativa.

Sendo assim, a delimitação da totalidade das características definidoras desse modo explicativo traz implicações para se pensar na própria identidade da Análise do Comportamento. Considerando a crítica de Tonneau e Sokolowski (2000) mencionada no início deste estudo, resta-nos questionar: Os desenvolvimentos recentes na pesquisa operante estão filiados a uma proposta selecionista? A Análise do Comportamento sustenta uma perspectiva selecionista, ou além da proposta de 'seleção por consequências', demandaria a adoção de outras propostas de explicação científica? Sem tentar esgotar as discussões sobre o tema, é válido mencionar que uma coerência teórica mínima interna dos fundamentos epistemológicos e filosóficos de uma ciência pode ser o caminho para uma autonomia científica. Talvez, uma incursão pela história da Biologia, com suas ramificações que vão desde a Biologia Funcional à Biologia Evolutiva, legitimando diferentes propostas de explicação científica, pode lançar luz sobre essas questões que perpassam as ciências comportamentais.

\section{REFERÊNCIAS}

Andery, M. A. P. A., Micheletto, N., \& Sério, T. M. A. P. (2000). A construção de seleção por consequências no trabalho de B. F. Skinner. Boletim Contexto, 21, 11-12.

Catania, A. C. (2001). Three types of selection and three centuries. International Journal of Psychology and Psychological Therapy, 1(2), 151-159.

Chiesa, M. (2006). Behaviorismo radical: A filosofia e a ciência (C. E. Cameschi, Trans.). Brasília: Celeiro/IBAC. (Trabalho original publicado em 1994).

Cleaveland, J, M. (2002). Beyond trial-and-error in a selectionist psychology. Behavior and Philosophy, 30, 73-99.

Cruz, R. N., \& Cillo, E. N. P. (2008). Do mecanicismo ao selecionismo: Uma breve contextualização da transição do Behaviorismo Radical. Psicologia: Teoria e Pesquisa, 24(3), 375-385. 
Darwin, C. (1859). On the origin of species by means of natural selection, or the preservation of favoured races in the struggle for life. London: John Murray.

Donahoe, J.W. (2003). Selectionism. In K. A. Lattal \& P. N. Chase (Eds.), Behavior theory and philosophy (pp. 103128). Dordrecht, Netherlands: Kluwer Academic Publishers.

Donahoe, J.W. (2012). Reflections on behavior analysis and evolutionary biology: A selective review of evolution since Darwin - the first 150 years. Jornal of the Experimental Analysis of Behavior, 97, 249-260.

Donahoe, J. W., Burgos, J. E., \& Palmer, D. C. (1992). A selectionist approach to reinforcement. Journal of the Experimental Analysis of Behavior, 60, 17-40.

Futuyma, D. J. (1998). Evolutionary biology (3rd ed.). Sunderland, MA: Sinauer.

Glenn, S. S. G. (2004). Individual behavior, culture, and social change. The Behavior Analyst, 27(2), 133-151.

Glenn, S. S. G., \& Madden, G. J. (1995). Units of interaction, evolution, and replication: Organic and behavioral parallels. The Behavior Analyst, 18, 237-252.

Holth, P. (2016). Levels of selection: A place for cultural selection. Norsk Tidsskrift for Atferdsanalyse, 43, 57-64.

Hull, D. L., Langman, R. E., \& Glenn, S. S. (2001). A general account of selection: Biology, immunology, and behavior. Behavioral and Brain Sciences, 24, 511-573.

Hunziker, M. H. L., \& Moreno, R. (2000). Análise da noção de variabilidade comportamental. Psicologia: Teoria $e$ Pesquisa, 16, 135-143.

Laurenti, C, \& Lopes, C. E. (2016). Metodologia da pesquisa conceitual em psicologia. In C. Laurenti, C. E. Lopes, \& S. F. Araujo (Orgs.), Pesquisa teórica em psicologia: Aspectos filosóficos e metodológicos (pp. 41-69). São Paulo: Hoegrefe.

Leão, M. F. F. C., \& Laurenti, C. (2009). Uma análise do modelo de explicação no behaviorismo radical: O estatuto do comportamento e a relação de dependência enre eventos. Interação em Psicologia, 13(1), 165-174.

Matos, M. A. (2003). A propósito de 'A construção de seleção por consequências no trabalho de B. F. Skinner' (Andery, Micheletto \& Sério, 2000). Boletim Contexto, 26, 4-6.
Micheletto, N. (1995). Uma questão de consequências: A elaboração da proposta metodológica de Skinner (Tese de Doutorado não publicada). Pontifícia Universidade Católica de São Paulo, São Paulo.

Moxley, R. A. (1996). The import of Skinner's three-term contingency. Behavior and Philosophy, 24(2), 145-167.

Moxley, R. A. (2001). Sources for Skinner's pragmatic selectionism in 1945. The Behavior Analyst, 24, 201-212.

Palmer, D. C., \& Donahoe, J. W. (1992). Essentialism and selectionism in cognitive science and behavior analysis. American Psychologist, 47, 1344-1358.

Reese, H. W. (2005). A conceptual analysis of selectionism. Behavioral Development Bulletin, 1(1), 08-16.

Skinner, B. F. (1981). Selection by consequences. Science, 213(4507), 501-504.

Skinner, B. F. (1984). Some consequences of selection. The Behavioral and Brain Sciences, 7, 502-510.

Skinner, B. F. (1990). Can psychology be a science of mind? American Psychologist, 45, 1206-1210.

Staddon, J. E. R., \& Simmelhag, V. L. (1971). The "superstition" experiment: A reexamination of its implications for the principles of adaptive behavior. Psychological Review, 78, 3-43.

Tonneau, F., \& Sokolowski, M. B. C. (2000). Pitfalls of behavioral selectionism. In: Perspectives in ethology (pp. 155-180). New Jersey: Prentice-Hall. (Trabalho original publicado em 1973).

Zilio, D., \& Carrara, K. (2008). Mentalismo e explicação do comportamento: aspectos da crítica behaviorista radical à ciência cognitiva. Acta Comportamentalia, 16(3), 399417. 